\title{
Agricultural Knowledge Transformation and China's Modern Development of Low Carbon Agriculture
}

\author{
Mo Lingna ${ }^{1}$, Li Jiadi ${ }^{2}$, Jiang Xijun ${ }^{3}$ \\ ${ }^{1}$ Female, Professor, Master of Economics, Vice President of Further Education College of Guangxi University of Science and \\ Technology, Guiping, Guangxi Province. Research area: Knowledge economy. \\ ${ }^{2}$ Male, Assistant, postgraduate of Lushan College Guangxi University of Science and Technology, Liuzhou, Guangxi Province. \\ Research area: Human resource management. \\ ${ }^{3}$ Male, Lecturer, Master of management, Further Education College of Guangxi University of Science and Technology, Guanyang, \\ Guangxi Province. Research area: Computer information management
}

\begin{abstract}
Century is the century of knowledge. Replacement process of social economic form is the process of the formation of new leading industries; also the process of the transformation of traditional industries with advanced technology in the new leading industry. In this thesis, based on system theory introduced in the background of knowledge-based, the process of China's traditional agricultural knowledge transformation and challenges are analyzed. It puts forward the development mode of China's green low carbon agriculture for the future. And finally it puts forward to promote low carbon agriculture (knowledgeable agriculture) development countermeasures and suggestions, in order to achieve the goal of knowledgeable transformation.

Index Terms - knowledgeable, agricultural knowledge transformation, modern low carbon agriculture, Development model

If the backward traditional agriculture is not allowed to exist in the industrial economic society, then backward traditional industry, agriculture, service industry are not allowed to exist in knowledge economy society either. So, from industrial economy to knowledge economy, on one hand we should vigorously develop high technology industry -- the leading industry of the knowledge economy, on the other hand we have to implement knowledge transformation of traditional industries. In early 1985, Qian Xuesen puts forward "create agricultural knowledge intensive industry, and it will cause the change of the social production system and economic structure, thereby giving rise to the sixth industrial revolution."
\end{abstract}

\section{Process, objectives and ways of agriculture intellectual transformation in China}

\subsection{The core essence and the relationship between reformation of agricultural knowledge and modern low carbon agriculture}

Knowledgeable agriculture is to develop high-tech industry so that it could become the dominant process, and play a decisive role in the national economy mainly. Its core is to develop new and high science and technology, and to make it industrialization. With high technology and equipment in all sectors of the national economy, we could realize the comprehensive coordinated development of economic, social, environmental and human.

The so-called knowledgeable transformation of traditional agriculture is in accordance with the demand of the knowledge economy society, to transform traditional agriculture with advanced technology. Then it could match the development of high technology industry, and form an agricultural industry structure of knowledge economy society.

Low carbon agriculture is modern agricultural form based on low consumption (energy, resources), low pollution (environment, product), and low emission (waste, $\mathrm{CO}_{2}$ and other greenhouse gases). The essence is through the efficient and clean use of energy. Low carbon and carbon free energy development and utilization, low carbonization and life achieve economic development mode shift of the mode of production from high carbon to low carbon. It is a win-win agricultural economic development form of economic and social development and ecological environmental protection. The relationship between agricultural knowledge transformation and modern low carbon agriculture is that agricultural knowledge is the foundation and prerequisite of low-carbon agriculture, while low-carbon agriculture is one of the goals of agricultural knowledge transformation. Only the realization of agricultural knowledge can we achieve low carbon agriculture.

\subsection{The course and challenges of China's traditional agricultural knowledge transformation}

Different from the developed countries, our agriculture has not yet completed the transformation of industrialization, and it is in a backward level on the whole. National agricultural development is very uneven. Some places in Southwest China is still in the slash-and-burn cultivation condition, and the eastern coastal areas have begun agricultural biological engineering practice, the difference between them are thousands of years. But in the recent 10 years, the agriculture of our country develops very fast, especially the modern agricultural industrialization. The supply of agricultural products changes from long-term shortage to basic balance of total amount, in order to enable our country to propose and implement "returning farmland to forest (grass), closing hillsides to facilitate afforestation, taking grain generation accounts, individual contract" measures, and implement the afforestation, greening desert and barren hills and wasteland policy. However, in a period, agricultural transformation of the task is heavy, because we need to put the agricultural industrialization and transformation of knowledge 
transformation together. In general, through experiencing both industrialization and knowledge transformation oriented reform, we can complete the knowledge transformation of agriculture.

\subsection{Target and way of Chinese traditional agricultural knowledge transformation}

The goal of agricultural knowledge transformation is the low carbon agriculture with high additional value of ecological agriculture according to the requirements of knowledge economy. The so-called refinement is intensive, which is intensive and meticulous farming by focusing on the use of resources, increase yield per unit area increased the total amount of agricultural products. This operation is called intensive management. China's past agriculture basically is extensive management, the irrigation is the water into the flowing everywhere, and the fertilizer is spreading fertilizer, which is typical of the extensive management practices. Intensive management is based on the crop cycle, fertilize and irrigate timely, appropriately, accurately.

To improve the technology content of agricultural products and value added by planting varieties, production of green food, then implementing the strategy of agricultural industrialization, founded the agricultural knowledge intensive industry. Both of which is the right way to agricultural knowledge transformation.

\section{The necessity and historical inevitability of developing modern low carbon agriculture}

The respiration of the organism itself, decay organisms, petroleum, coal, combustion and other organisms, burning of coal, oil, natural gas and trees, produce a large amount of carbon dioxide into the atmosphere after the earth's carbon cycle imbalance. It changes the ecological balance of the earth's biosphere, which greatly exceeds the earth originally carbon fixation capacity.

In 1850 before the industrial revolution, the amount of carbon dioxide in the atmosphere is $250 \mathrm{ppm}$, and this number has reached $380 \mathrm{ppm}$ in 2005, which has increased by $25 \%$. It is far more than the historical record that scientists may survey of the past 160000 years, and no signs of slowing down.

As the foundation of the national economy, agriculture is an important source of greenhouse gases. Studies have shown that in our country, agricultural greenhouse gas emissions accounted for about $17 \%$ of the emissions (Gao Wangsheng, 2009). Agricultural sources of emissions of $\mathrm{CO}_{2}$ and $\mathrm{CH}$ respectively of anthropogenic greenhouse gas emissions of $21 \%-25 \%$ and $57 \%$, Agro ecosystem carbon pool is an important component of the global carbon pool and terrestrial ecosystem carbon pool (Zhao Rongqin,.2004). Thus, the formation of carbon dioxide and its distribution in air and water is unabated, which threaten growing crises. In order to maintain the ecological balance of the earth's biosphere, on one hand we should vigorously develop modern low carbon industry, on the other hand, we have to take positive and effective measures to promote the circulation of carbon.

\section{Chinese development models of green low carbon agriculture in the future}

Future Chinese knowledge agriculture will consist of three parts, one is the green open agriculture; two is white factory farming; three is the blue ocean agriculture. This thesis is mainly about green open agriculture.

\section{1 development of ecological agriculture}

Ecological agriculture is based on ecology theory, formed in a specific area of economic, social and ecological benefits of the agriculture. The biggest characteristic of ecological agriculture is the ecological cycle which is formed between the agricultural production and the surrounding environment. For example, cattle and sheep eat grass to growth, reproduction, and their dung is pasture fertilizer, which makes grass grow. Thus it forms an ecological cycle to promote the coordinated development of cattle and sheep and pasture. Ecological agriculture is intensive agricultural consciously according to law of ecology, ecological economics and system engineering methods to set up the farming industry combined with each other and each with a focus on high energy, high efficiency of knowledge intensive. Through the construction of ecological agriculture, can make full use of solar energy, bio energy, and flow and accelerate the circulation of matter and energy within the ecological system, to achieve better economic benefit, social benefit, ecological benefit and environmental benefit, and make it organically. The development of ecological agriculture is a necessary requirement to achieve the sustainable development of China, but the ultimate goal of agricultural knowledge transformation to achieve. The development of ecological agriculture relies on scientific and technological progress, scientific and increase of cultural qualities of the entire people. Not two or lack of one, it will not be the development of ecological agriculture.

\subsection{Development of carbon cycle and low carbon agriculture}

\subsubsection{Meaning and model of carbon cycle}

The carbon cycle on the earth mainly refers to the formation and transformation of carbon dioxide, as shown below. One is the formation of carbon dioxide; the other is carbon dioxide into other substances. There is mutual transformation and balance between each other, otherwise normal circulation ceases to exist.

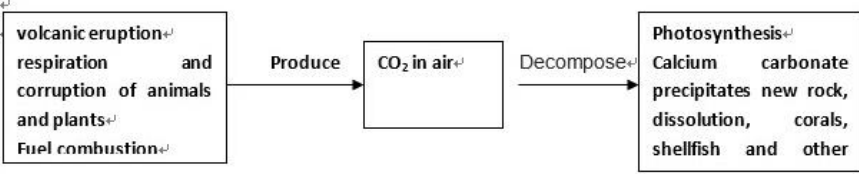

3.2.2 The basic principle of the carbon cycle and carbon cycle system

The basic principle of the carbon cycle is $\mathrm{CO} 2$ in the atmosphere produces glucose (C6H12O6) by green plants, algae photosynthesis, photosynthetic bacteria, then glucose (C6H12O6) further into sugar, protein, fat and nucleic acid 
and other organic matter and oxygen, these organic compounds and oxygen is conducive to the growth of plants and animals, the results further promote the photosynthesis of plants, and ultimately achieve carbon reduction and carbon sequestration goal.

More glucose $\left(\mathrm{C}_{6} \mathrm{H}_{12} \mathrm{O}_{6}\right)$ can promote the growth of plants and animals. Plants grow faster and promote the photosynthesis, and then it begins a new carbon cycle. Carbon cycle system as shown below:

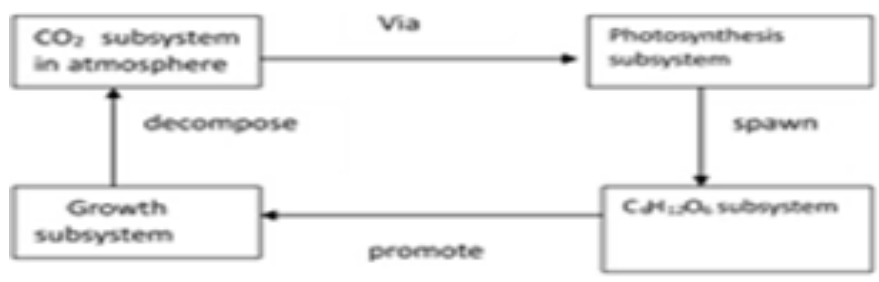

From the picture above we can find that the carbon cycle system consists of four subsystems; the $\mathrm{CO}_{2}$ subsystem in the atmosphere, photosynthesis subsystem of plants, animal and plant growth subsystem and $\mathrm{C}_{6} \mathrm{H}_{12} \mathrm{O}_{6}$ (glucose) organic subsystem. Each subsystem has the output and the input, the output of a system is a subsystem of the input, between each subsystem is designed and each other and balance, they finally form the carbon cycle system.

\subsubsection{Carbon fixation and reduction (mainly $\mathrm{CO}_{2}$ ) pathway}

It can be seen from the model of carbon cycle and circulation system, carbon fixation and reduction (mainly $\mathrm{CO}_{2}$ ) way:

(1) Through photosynthesis (green plants, algae, and photosynthetic bacteria), $\mathrm{CO}_{2}$ and water turns into sugar, fat, protein and other organic matter and oxygen, the main power keeps the earth full of vitality.

Organism is just protein body composed of nucleic acid and protein containing nitrogen. Nitrogen is very important to the organism. No nitrogen, there would be no life, including animal, plant, fungi, algae, bacteria, viruses and other all the organism. But the nitrogen in the air $\left(\mathrm{N}_{2}\right)$ is an inert gas, which can not be directly used in most biological. So only through chemical production of the nitrogen in the air $\left(\mathrm{N}_{2}\right)$ people can form nitrogen fertilizer, the second way is to produce ammonia NH3 by lightning, and the three is nitrogen fixation, and then the nitrogen circulation system forms, as shown below:

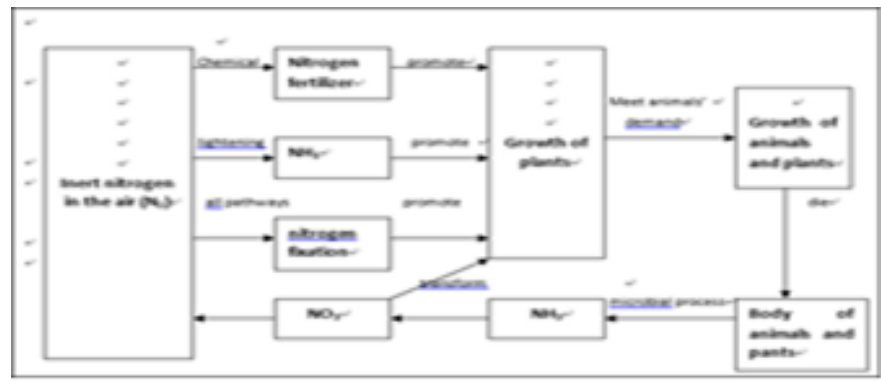

Nitrogen ways which plants and algae can use:

Biological nitrogen fixation: leguminous plants and a few other higher plants by fixing atmospheric nitrogen fixation rhizobia in nitrogen (limited).

Industrial nitrogen fixation: human by industrial means of synthetic ammonia or ammonia nitrogen fertilizer in the atmosphere (unlimited).

Atmospheric nitrogen fixation: lightning to nitrogen oxide in the atmosphere to nitrate (limited).

Magmatic nitrogen fixation: volcano eruptions of magma to fix atmospheric nitrogen in the (limited).

Nitrogen fixing microorganisms: nitrogen fixing bacteria, photosynthetic bacteria, Rhizobium bacteria, actinomycetes, cyanobacteria (limited).

Nitrogen in the air $\left(\mathrm{N}_{2}\right)$ only into such compounds can be utilized by plants, and atmospheric nitrogen fixation, biological nitrogen fixation, nitrogen fixation and nitrogen fixing microorganisms magma are limited, therefore, no modern chemical fertilizer, especially nitrogen fertilizer industry, there is no modern agriculture.

In addition to nitrogen fertilizer, modern chemical industry includes potash and phosphate fertilizer, etc.. To develop modern chemical industry and support the development of the modern green plant industry, so that we can develop plant photosynthesis (green plants, algae, photosynthetic bacteria).

Therefore, carbon fixation and reduction (mainly $\mathrm{CO}_{2}$ ) pathway is mainly through the following system to solve, as shown below:

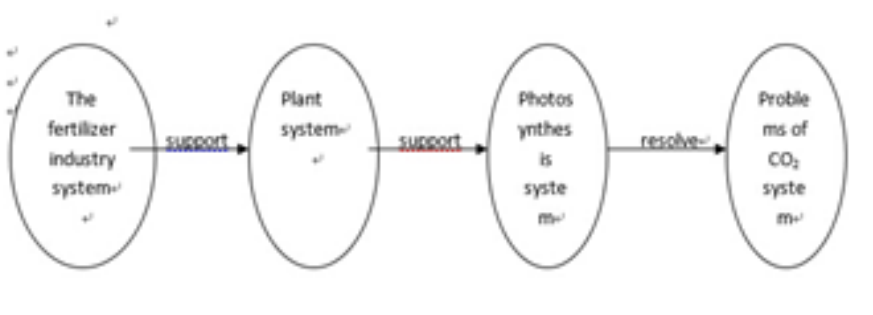

(2)Scientific fertilization and use of chemical fertilizer, pesticide, carbon fixation

The purpose of scientific fertilization can ensure the crops on nutrient needs, but also can use less fertilizer, and prevent hardening of the soil. Methods of scientific fertilization are on the determination of soil nutrient release. Then according to the specific demand of crops in different growth period, people can save fertilizer, and also can greatly reduce greenhouse gas emissions.

(3)Recycling of carbon resources promotion

Agricultural production of residual waste, agricultural and sideline products turns into useful raw materials through certain technical processing and the planting, breeding and processing and production process. New product and raw material can return into use, which forms a recycling of carbon resources. Agricultural production in a variety of waste turns harm into good, and turns waste into treasure, cyclic utilization, depth. 
(4)The development of non carbon energy

Development of biological organisms, solar energy, wind energy, fuel, tidal energy, hydropower and other non carbon cycle energy, make full use of solar energy and other new energy to replace traditional energy sources.

(5) Active promotion of straw to field technology, green manure planting and application technology, biogas manure application technology, commercial organic fertilizer production and application technology.

\section{Countermeasures and suggestions of promoting the development of agriculture of low carbon}

At present, main rural labor are people of 1950s, 1960s and 1970s, because 1980s of 800 million farmers become the main force of those who work in cities. Although their educational level not that low, their subjective intention to accept fresh things are relatively low, which formed the inherent barriers to promote low carbon agricultural advanced technology, especially in remote and less developed areas. The simplest example is the rice seedling throwing technique, the technology can guarantee the grain yield not affected under the premise, which greatly improves efficiency and reduces labor intensity. The benefit is obviously. But in many rural areas it doesn't get the comprehensive application, of which there is the concept of reason. So, for the majority of the peasants, they need to change the past traditional agricultural thought. Therefore, through a variety of medias and regularly organize training courses, lectures and other forms, we have to change the public and social concepts, and improve the masses of farmers awareness and understanding of low carbon agriculture. At the same time, the agricultural departments at all levels often bring technology to rural areas. The government set special funds to support the government, especially acceptable families of advanced technology with advanced concept. Let some people successfully test and benefit from it, so as to lead others, and implement the comprehensive promotion. The simple preaching is very difficult and ineffective in rural areas, farmers need typical effect.

\section{References}

[1] Mo Lingna, Shi Lingfang. Some thoughts on the transformation of traditional industry knowledge. Financial and economic, 2005(7)

[2] Zhao Qiguo, Qian Haiyan. Thinking on economic and agricultural development in low carbon. Chinese Journal of ecology. 2009(9)

[3] Wang Haiwen. Future prospect of low carbon agriculture. Agricultural Outlook. 2010(10)

[4] Mo Lingna, Li Zhongqian. The market characteristics of the knowledge economy. Modernization of shopping malls. 2005(8)

[5] Lin Chaowen, Zhu Yongqing. Some suggestions to accelerate the development of low carbon agriculture in our province. Sichuan Science and Technology News, 2010(5)

[6] Wang Haiwen. The development of low carbon agriculture government as rural economy and science and technology. 2010(8)

[7] Wang Haiwen. Actively promote the development of low carbon agriculture. The theory construction. 2012(10)

[8] Jin Pan. The development of low carbon agriculture to promote rural energy-saving emission reduction. Agricultural Engineering Technology (new energy industry). 2011(2)

[9] Zhang Yunlong, Du Dengke. The main way to develop low carbon agriculture in Changde city. Crop research. 2010(10) 